\title{
CONSTRUÇÃO DE CONFIANÇA E TRANSPARÊNCIA MILITAR NA UNASUL: AVANÇOS E DESAFIOS
}

\section{Trust Building and Military Transparency in UNASUR: achievements and challenges}

\author{
Diego Trindade d'Ávila Magalhães ${ }^{1}$ \\ Rafael Lemos da Silva ${ }^{2}$ \\ Júlia de Mello Feliciano ${ }^{3}$
}

\section{Introdução}

Em 2012, o Conselho de Defesa Sul-Americano (CDS) e o seu Centro de Estudos Estratégicos de Defesa (CEED) publicaram o primeiro Registro Sul-Americano de Gastos Agregados em Defesa 2006-2010, que é um marco no desenvolvimento da agenda da transparência militar entre os Estados da América do Sul. No contexto da integração regional sob a União de Nações Sul-Americanas (UNASUL), a promoção da transparência militar é uma das formas de afastar o risco de guerra e de criar um ambiente propício à cooperação e ao desenvolvimento.

Tendo em vista aqueles objetivos, os países sul-americanos desenvolveram "uma definição comum de gastos de defesa, uma metodologia padronizada para representar a informação e um mecanismo anual de apresentação" (FORTI, 2014).

\footnotetext{
${ }^{1}$ Professor de Relações Internacionais e Coordenador da Especialização em Diplomacia e Relações Internacionais da Universidade Federal de Goiás (UFG). Doutor em Estudos Estratégicos Internacionais pela Universidade Federal do Rio Grande do Sul (UFRGS), Bacharel e Mestre em Relações Internacionais pela Universidade de Brasília (UnB), e Membro do Núcleo de Estudos Globais. Email: diegotdm@gmail.com

${ }^{2}$ Rafael Lemos da Silva é Graduando em Relações Internacionais pela Universidade Federal de Santa Maria (UFSM), com período sanduíche na University of Florida, Estados Unidos (2015-2016). Foi bolsista do programa Jovens Talentos para a Ciência da CAPES no Grupo de Pesquisa Comunicação, Identidades e Fronteiras da UFSM. Neste grupo publicou o artigo intitulado “A posição da revista Veja no conflito fronteiriço entre brasileiros e paraguaios” com colaboração de Ada Cristina Machado Silveira, Isabel Guimarães, Aline Dalmolin e Andressa Foggiato, o qual pode ser encontrado nos anais do XXXVII Congresso Brasileiro de Ciências da Comunicação que ocorreu em 2014 em Foz do Iguaçu. Atualmente faz parte do Grupo de Estudos em Capacidade Estatal, Segurança e Defesa (GECAP) onde desenvolve pesquisas sobre Oriente Médio e segurança internacional. Email: rafa.lemos.silva@gmail.com

${ }^{3}$ Graduanda do $8^{\circ}$ semestre de Relações Internacionais da Universidade Federal de Santa Maria (UFSM), com período sanduíche na Universidad de Buenos Aires (UBA), Argentina, como bolsista da Asociación de Universidades del Grupo Montevideo (AUGM) durante o ano de 2015. Fez parte do grupo de Estudos em capacidade estatal, Segurança e Defesa (GECAP) durante o ano de 2016, onde produziu o artigo intitulado "O Desenvolvimento do Polo de Defesa de Santa Maria e as Simulações Militares: A Inserção do Brasil na Era Digital”, artigo colaborativo com Augusto César Dall'agnol, Lucas Otesbelgue Henes, Gustavo Manduré e Rafael Severo, sob orientação do prof. Dr. Igor Castellano da Silva. O trabalho foi apresentado no XII Congresso Acadêmico de Defesa Nacional (CADN) na Escola Naval do Rio de Janeiro e na $31^{\circ}$ Jornada Acadêmica Integrada (JAI UFSM) e pode ser encontrado nos anais de ambos os eventos. Email: jmf.feliciano@gmail.com
} 
Para os fins do Registro Sul-Americano de Gastos Agregados em Defesa, entende-se por gastos de defesa todos os recursos assignados pelo Estado para o financiamento das atividades que compreendem a segurança externa da Nação. Inclui também a assistência externa recebida para esse fim (monetária ou não monetária) (CEED, 2011, p. 9).

Essa definição de gasto de defesa foi inspirada na experiência bilateral entre Argentina e Chile de 1999 a 2001 (REZENDE, 2015; SAINT-PIERRE; PALACIOS JR., 2014). Ambos trabalharam com a ideia de que “[...] defesa era o conjunto de atividades que buscavam garantir a soberania nacional. Todos os gastos que almejassem tal objetivo compreendiam-se no campo da defesa." (SILVA, 2013, p. 41). Isso inclui, segundo um ex-diretor do CEED, gastos executados (não apenas planejados) em todas as instituições envolvidas diretamente em atividades de segurança e defesa contra ameaças externas (FORTI, 2014). Com base na metodologia da Comissão Econômica para América Latina e Caribe (CEPAL) (ECLAC, 2005), o CDS classifica os gastos da seguinte forma: remuneração de pessoal, operações e manutenção (bens de consumo e serviços), investimentos (sistemas de armas, infraestrutura física e outros), e pesquisa e desenvolvimento (CEED, 2011, p. 9).

Apesar da sua pertinência para a consolidação de relações pacíficas entre Estados, ainda há poucos estudos sobre a transparência militar na América do Sul. Pesquisas recentes que tocam no assunto focalizam questões mais amplas, tais como o complexo regional de segurança sul-americano (FUCCILLE; REZENDE, 2013), o papel do Brasil na cooperação em defesa e na construção de confiança na região (ABDUL-HAK, 2013; PAGLIARI, 2009; REZENDE, 2015; TEIXEIRA, 2011), a construção de confiança e a alocação setorial de gastos militares sul-americanos (SAINT-PIERRE; PALACIOS JR., 2014) e as dinâmicas e as tendências recentes dos gastos militares por país (VILLA; VIGGIANO, 2012).

Para complementar esses estudos e propiciar futuras análises explicativas, este artigo concentra-se na construção, no significado e nos desafios da agenda da transparência militar na América do Sul. A agenda da transparência militar consiste no conjunto de práticas por meio das quais dois ou mais Estados compartilham o conteúdo de acordos militares e informações relativas a gastos militares. Ressalta-se que não se trata apenas de compartilhar informações sobre gastos militares, mas também sobre acordos militares, conforme será apresentado adiante.

Convém problematizar, a princípio, a construção da agenda. Por um lado, o CDS e o CEED (2012, p. 53) reconhecem que o tratamento tema

[...] é fruto da decisão e da vontade política dos Estados membros do CDS-UNASUL, constituindo uma experiência inédita em matéria de transparência e níveis de confiança mútua alcançados entre as nações sul-americanas, impensados há tão poucos anos atrás.

Por outro lado, há sinais de que a vontade política dos sul-americanos é insuficiente para avançar nas agendas do CDS (L. Saint-Pierre apud REZENDE, 2015). Nesse sentido, questiona-se até que ponto a agenda da transparência militar continuará dependendo mais da vontade política conjuntural dos Estados da região, em vez de instituições consolidadas a cargo de continuar e aprofundar os avanços.

Quanto ao significado atribuído à agenda, a UNASUL, o CDS e o CEED expressamente reconhecem a clara correlação direta entre a promoção da transparência militar e a construção de confiança. Se gastos de 
defesa e acordos militares podem gerar desconfiança entre Estados, ações de transparência implicam o compartilhamento de informações e, assim, geram confiança (SILVA, 2013). Contudo, alguns Estados sulamericanos relutam em aprofundar o nível de transparência militar devido à existência de problemas de segurança com países vizinhos.

Em suma, a agenda da transparência militar está entre as medidas de construção de confiança necessárias para a paz na região, mas há incertezas quanto ao futuro avanço nesse tema. Por isso, este artigo discute as seguintes questões: como se constituiu a agenda sul-americana de transparência militar? Que significado os membros da UNASUL atribuem à promoção da transparência militar? Quais são os desafios que os Estados sul-americanos enfrentam no desenvolvimento dessa agenda? As respostas fundamentam-se basicamente em revisão bibliográfica e em documentos derivados de Estados sul-americanos, da UNASULCDS e do CEED.

Na primeira seção, apresentam-se entendimentos teóricos acerca da relação entre a transparência militar e a construção de confiança entre Estados. Na segunda, analisam-se o surgimento e os objetivos da UNASUL e do CDS, para contextualizar a origem daquela agenda. A terceira seção discorre sobre o tratamento dado pelo CDS à agenda, em resposta a crises sul-americanas. Por fim, analisam-se os desafios que os Estados sul-americanos precisam enfrentar para aprofundar a transparência militar e, assim, a confiança recíproca.

\section{Construção de confiança via transparência militar}

As ações de transparência militar, por definição, resultam na diminuição da incerteza de um Estado acerca das intenções de outro. Por isso, são parte do conjunto de medidas de construção de confiança que conduzem à dessecuritização das relações interestatais. O conceito de securitização consiste em um processo marcado por atitudes que fogem das regras institucional ou costumeiramente estabelecidas (BUZAN; WEAVER; WILDE, 2003) e que propiciam uma abordagem militar do problema. A securitização ocorre quando "[...] uma questão se transforma em ameaça existencial a um objeto referente da segurança" (ALSINA JR. 2006, p. 26). Assim, uma questão securitizada refere-se a uma causa pela qual uma nação acredita que vale a pena mobilizar recursos extraordinários, incluindo força militar. A dessecuritização refere-se ao inverso e está associada a um processo de construção de confiança interestatal.

A CEPAL parte da definição da Ata de Helsinki sobre medidas de construção de confiança, que incluem as medidas que visam à redução dos “[...] perigos de conflitos armados e do desentendimento ou do erro de cálculo de atividades militares que podem dar ensejo a apreensão" (OSCE, 1975 apud ECLAC, 2005, p. 9). Incluem-se, por exemplo, medidas de comunicação que contribuem para dispersar tensões, medidas de transparência para promover a troca de dados sobre capacidades e atividades militares e medidas de verificação de dados a título de comparação com requisitos de tratados internacionais, todas essas medidas acabam por ajudar a criar previsibilidade no comportamento de Estados, facilitando o contato, estabelecendo regras e padrões de comportamento para as forças armadas, para os políticos e para o pessoal diplomático (ECLAC, 2005, p. 9). 
Cottey e Forster (apud REZENDE, 2015) associam esse tipo de cooperação militar no contexto de uma "nova diplomacia de defesa" com a finalidade de "engajamento estratégico": a busca por cooperação militar com antigos ou potenciais oponentes, a fim de prevenir conflitos, mostrando boa vontade e comprometimento para criação de uma confiança mútua, introduzindo transparência em questões de defesa (em especial na posse de recursos e intenções), construindo ou reforçando interesses mútuos, mudando as mentalidades das forças militares parceiras, apoiando reformas de defesa nos parceiros, ou incentivando a cooperação em outras áreas. Em suma, trata-se de uma diplomacia de defesa "orientada para a cooperação militar de Forças Armadas em tempos de paz, como uma ferramenta de política externa e de segurança” (REZENDE, 2015, p. 26).

Naturalmente, as ações de transparência militar inserem-se nesse tipo de diplomacia. Sob a ótica clássica de Sun Tzu (2005), boa parte do segredo para a vitória em uma guerra é o uso da surpresa e da dissimulação (da trapaça, do engano). Nesse sentido, a publicação e o compartilhamento de informações relativas ao setor de defesa favoreceria o planejamento estratégico de forças potencialmente hostis, o que comprometeria questões de segurança nacional, por isso, os governos restringem o acesso a essas informações (WEZEMAN; WEZEMAN, 2014).

A revelação de acordos, dados e planos estratégicos de um Estado para outro diminui as chances de vitória daquele Estado em eventual guerra. Portanto, ao compartilharem tais informações, os Estados manifestam a sua intenção de manter relações pacíficas e de comportar-se como membros de uma comunidade. A transparência em relação a políticas de defesa, gastos militares e capacidades militares é uma demonstração de confiança entre dois ou mais Estados e, assim, elemento essencial para a construção de confiança entre eles (Michael Moodie apud ABDUL-HAK, 2013; WEZEMAN; WEZEMAN, 2014).

A construção da confiança pela promoção da transparência militar pode ser confundida com um dano à soberania ou um risco aos ganhos de um Estado. Todavia, ações de transparência resultam de uma decisão soberana para a construção de confiança e de relações cooperativas entre um grupo de Estados.

\section{União de Nações Sul-Americanas e Conselho de defesa sul-americano}

Na segunda metade dos anos 1990, a articulação sul-americana foi inicialmente favorecida pela necessidade de coordenar posições negociadoras frente à proposta de Área de Livre Comércio das Américas (ALCA) e pelo interesse comum em projetos de infraestrutura (COUTO, 2009). Nesse sentido, a I Reunião de Presidentes da América do Sul, realizada em Brasília no ano 2000, viabilizou o projeto da Iniciativa para a Integração da Infraestrutura Regional Sul-Americana (IIRSA). A IIRSA justificou, em parte, a falta de um convite ao presidente do México: os projetos de infraestrutura seriam financeiramente inviáveis se adotassem o conceito de América Latina, haja vista os já imensos eixos de integração física de alcance sulamericano (LIMA, 2007).

No século XXI, mudanças de governo em vários países sul-americanos - Argentina (2003), Bolívia (2006), Brasil (2003), Chile (2006), Equador (2007), Paraguai (2008), Peru (2006), Uruguai (2005) e Venezuela (1999) - propiciaram a convergência de posições contrárias à ALCA e favoráveis a um ambicioso projeto de 
integração regional. Em 2004, a III Reunião de Presidentes da América do Sul, em Cuzco, ampliou o escopo do projeto sul-americano e criou a Comunidade Sul-Americana de Nações (CASA) sob quatro pilares: livrecomércio, concertação política, integração física e integração energética (DINIZ, 2006, p. 47). Até então, a agenda de defesa estava apenas implícita, vaga e difusa na ideia de concertação. Além disso, a CASA parecia para muitos um projeto eminentemente brasileiro (BERNAL-MEZA, 2008), e era essa desconfiança que os países sul-americanos precisavam enfrentar.

Lançada em 2007 e institucionalizada em 2008, a UNASUL continha metas ainda mais ambiciosas do que a CASA, que deixou de existir. Assim, em menos de uma década, os 12 países da América do Sul Argentina, Bolívia, Brasil, Chile, Colômbia, Equador, Guiana, Paraguai, Peru, Suriname, Uruguai e Venezuela - criaram o costume de encontros presidenciais sob uma organização com personalidade jurídica internacional e com uma agenda multitemática discutida em órgãos específicos.

O tratado constitutivo da UNASUL estabelece os seguintes princípios: soberania; integridade e inviolabilidade territorial dos Estados; autodeterminação dos povos; solidariedade; cooperação; paz; participação cidadã e pluralismo; direitos humanos universais, indivisíveis e interdependentes; redução das assimetrias e harmonia com a natureza para um desenvolvimento sustentável (BRASIL, 2008). Esses princípios são diretamente aplicáveis ao tema da transparência militar discutido no CDS, haja vista as diversas implicações políticas, estratégicas, sociais e econômicas desta agenda.

A UNASUL e o CDS imediatamente se tornaram o foro preferencial de debate sobre questões de segurança (ABDUL-HAK, 2013; FUCCILLE; REZENDE, 2013; PAGLIARI, 2009; REZENDE, 2015; SAINTPIERRE; PALACIOS JR., 2014), minimizando, assim, o papel da Organização dos Estados Americanos e mesmo o do Grupo do Rio, e afastando a possibilidade de interferências exógenas na solução de conflitos regionais. De fato, atualmente, tanto a origem quanto a solução dos principais focos de insegurança na América do Sul se encontram na própria região.

O primeiro desafio da UNASUL foi conciliar a Colômbia e o Equador após o ataque aéreo daquele país a um acampamento das Forças Armadas Revolucionárias da Colômbia (FARC) em território equatoriano em 2008 (FOLHA DE SÃO PAULO, 2008). Seguindo protesto do Equador e a ruptura de relações diplomáticas, a Venezuela entendeu que ação colombiana foi uma grave violação da soberania equatoriana e advertiu a Colômbia a não invadir a Venezuela. A Colômbia assumiu a responsabilidade pelos ataques e alegou a necessidade de combater o terrorismo, o qual não possui fronteiras. A UNASUL contribuiu para impedir o aprofundamento do processo de securitização fomentado pela coalizão Equador-Venezuela. Como resultado, as relações diplomáticas entre Colômbia e Equador foram retomadas em setembro de 2009 (ESTADÃO, 2009a).

Paralelamente a esse desafio, estava a negociação de acordo militar entre a Colômbia e os Estados Unidos, que permitia a utilização de sete bases militares colombianas: as bases áreas de Palanquero, Malambo e Apíay, as bases navais de Cartagena e Bahía Málaga, e os fortes militares de Tolemaida e Larandia (SANJUÁN, 2012; SILVA, 2013). A presença dos norte-americanos na Colômbia estava amparada pelo Plano Colômbia de 1999, cuja renovação preocupava os países vizinhos, assim como a possibilidade de 
que essas bases fossem usadas pelos EUA com propósitos distintos do combate às narco-guerrilhas (PAGLIARI, 2009). Os EUA, no pós-Guerra Fria, preocupavam-se com a América Latina por causa das questões de drogas e de migração (BUZAN; WEAVER, 2003). Apesar da aproximação Colômbia-EUA e de resultados positivos do Plano Colômbia no combate ao narco-tráfico, a intenção de renovar o acordo chocou com as pressões dos membros da UNASUL, que queriam esclarecimentos. Ademais, a Corte Constitucional da Colômbia declarou inválido o acordo, porque não tinha sido apresentado antes ao Congresso da República (SANJUÁN, 2012).

Em 2009, a UNASUL priorizou a discussão acerca de garantias colombianas-estadunidenses sobre a instalação das bases norte-americanas em território colombiano, ocasião que elevou a prioridade conferida à pauta sobre transparência militar na UNASUL (FOLHA DE SÃO PAULO, 2009). No mesmo ano, os membros da UNASUL demandaram do Brasil pronunciamento a respeito do acordo firmado com a França sobre a aquisição de helicópteros, submarinos convencionais e a construção de um submarino de propulsão nuclear; e com os Estados Unidos sobre exercícios militares e comércio de armamentos. A Venezuela também foi pressionada a aumentar a transparência de seus acordos com a Rússia para a compra de armamentos (entre outros, 24 caças e 100 mil fuzis) (REUTERS, 2009). Caracas, por sua vez, convidou todos os Estados membros a revelarem seus acordos militares, como uma forma de demonstrar confiança (ESTADÃO, 2009b).

A UNASUL instou os seus membros a informarem acordos militares e compras de armamentos. Então, Brasil, Colômbia, Venezuela e outros países sul-americanos revelaram os detalhes das negociações e dos acordos militares na UNASUL. Assim, a partir de 2009, criou-se o entendimento de que os acordos firmados com países exógenos à região, além da presença de forças militares estrangeiras não podem ameaçar a soberania e integridade de qualquer nação sul-americana e, em consequência, a paz e segurança na região.

As interações com atores extrarregionais estão, portanto, inseridas nessa lógica, principalmente, como fornecedores de armamentos e parceiros em treinamentos militares. Os EUA continuam tendo forte presença na América do Sul, em exercícios militares, programas de formação e capacitação, e fornecedores de armas (ABDUL-HAK, 2013; REZENDE, 2015; VILLA; VIGGIANO, 2012). A União Europeia figura como a principal fornecedora de armamentos para a região, especialmente para países como o Brasil, a Colômbia e o Chile (ELLIS, 2015). A Rússia possui como principal parceira na região a Venezuela, vendendo-lhe, por exemplo, helicópteros militares e mísseis (NEGROPONTE, 2015), bem como realizando exercícios militares com forças navais. É crescente a presença da China no comércio de armas com a América do Sul, sobretudo com a Venezuela e a Bolívia (BRENDT et al, 2012).

Já era possível perceber que experiências positivas ocorridas no Cone Sul poderiam também ocorrer na América do Sul como um todo. Argentina e Brasil planejavam, desde 2007, em cooperação com a França, construir um submarino nuclear a partir da constituição de uma empresa binacional (BERNAL-MEZA, 2008; REZENDE, 2015). Em vez de provocar desconfiança, a possibilidade de aquisição de caças franceses pelo Brasil em 2010 no âmbito do Programa FX-2 gerou o interesse do Chile pela cooperação entre indústrias de defesa (PASSOS; MENEZES, 2009). 
Parte da literatura indica que o entendimento e a estabilidade na América do Sul podem ser prejudicados pelas assimetrias (geográficas, econômicas, demográficas, militares, etc.) entre os Estados sulamericanos (CASTILLO, 2008). Contudo, essas iniciativas no Cone Sul e as propostas dos Planos de Ação do CDS têm sido menos afetadas pelas assimetrias do que por constrangimentos orçamentários e pelo recuo do Brasil em seu papel de fiador da cooperação (REZENDE, 2015).

De modo geral, os Estados da região percebem que a integração regional pode potencializar estrategicamente o poder de barganha de cada um deles (BANDEIRA, 2006; CERVO, 2008; LIMA, 2007), e nisso a UNASUL cumpriria papel central, estimulando a concertação política e fortalecendo a autonomia da região diante de potências externas. Além disso, o CDS demonstrou ter caráter preventivo, atuando como um mecanismo de solução de controvérsias e de construção de confiança. A heterogeneidade de orientações ideológicas e de percepções de ameaça, as divergências no tratamento de conflitos regionais e a persistência de conflitos territoriais (CASTILLO, 2008) são desafios que implicitamente aparecem nesta seção, que contextualiza o surgimento da UNASUL.

\section{Conselho de Defesa sul-americano e transparência militar}

Assim como a própria UNASUL, o CDS se apoia nas ideias de diálogo para a resolução de controvérsias regionais, de comprometimento com a proteção da democracia e de respeito aos direitos humanos, além de promover a paz e de reafirmar o continente como região livre de armas nucleares. Este conselho prevê, ainda, a troca de informações sobre as intenções militares dos países membros e do conhecimento acerca de produção de armamentos, com o intuito de fomentar a construção da confiança e da transparência que são essenciais para o processo de integração nesta área da alta política (BRASIL, 2008). Um dos princípios pelos quais o CDS atua é o fortalecimento do diálogo e do consenso em matéria de defesa mediante a promoção de medidas de confiança e transparência (BRASIL, 2008). Para tais medidas foram estabelecidos mecanismos de fortalecimento de confiança e segurança quanto às atividades militares, sejam elas entre os próprios países sul-americanos ou entre estes e terceiros.

Na Reunião Extraordinária de Chefes de Estado e de Governo da UNASUL de San Carlos de Bariloche e na II Reunião Extraordinária de Ministros das Relações Exteriores e da Defesa da União de Nações SulAmericanas (UNASUL) de Quito, em agosto e novembro de 2009, respectivamente, firmaram-se acordos consensuais pelos quais qualquer manobra, emprego ou exercício militar, terrestre, aéreo ou naval realizado por um país membro da UNASUL em zona fronteiriça terá de ser informado com a maior antecedência possível aos demais membros e à UNASUL. E essa notificação deverá conter dados da localização, do número de efetivos e da natureza e quantidade de equipamentos que a atividade utilizará. Tanto o Estado notificado quanto o notificante devem se comprometer a respeitar a confidencialidade da informação, no que diz respeito a terceiros.

Esse tipo de cooperação envolvendo a troca de informações sensíveis indica a existência de uma identidade que inclui os países da região como "nós" e se refere aos “outros" como "extrarregionais". Informações sobre o número de efetivos e de equipamentos militares, a sua localização e os propósitos das 
suas atividades denotam a existência de confiança recíproca e de um incipiente processo de planejamento militar conjunto, tendo em vista a promoção da participação dos Estados sul-americanos conjuntamente em exercícios militares internacionais. Este tópico refere-se ao compromisso dos países sul-americanos de convidar observadores militares dos membros da UNASUL a participar de exercícios militares que envolvam parceiros extrarregionais. Por fim, complementando a ideia de planejamento militar conjunto, a UNASUL tem promovido mecanismos de comunicação entre forças militares de fronteira, para a coordenação das suas atividades.

Nesse sentido, percebe-se que a necessidade do CDS adveio das percepções sul-americanas de ameaças externas à região, cujos recursos naturais atraem a cobiça de grandes potências (BANDEIRA, 2006). Nenhum Estado sul-americano em particular tem poder suficiente para desafiar alguma dessas potências, o que torna imprescindível a integração regional como maneira de potencializar coletivamente as capacidades de defesa de cada Estado da UNASUL (BANDEIRA, 2006; CERVO, 2008; LIMA, 2007).

Evidenciou-se também interesse comum em evitar o desenvolvimento de uma corrida armamentista na América do Sul, no contexto em que as combalidas forças armadas da região estavam reequipando e modernizando armamentos. Era necessário afastar percepções de ameaça recíproca e interpretações equivocadas sobre o comportamento do Estado vizinho. A transparência militar foi a resposta a esse desafio: o intercâmbio de tecnologia militar e pessoal entre seus membros, a explicação das intenções, manobras e capacidades dos exercícios militares de cada país como mecanismo de transparência, reforçando a ideia de segurança regional conjunta, tornariam possível avaliar os objetivos de determinadas ações e os cenários de conflitos e controvérsias, fomentando a confiança mútua dentro do bloco e evitando más interpretações, ações equivocadas e também quaisquer incidentes diplomáticos (VILLA, 2008).

A transparência militar indica intenções pacíficas recíprocas entre membros de uma comunidade, que buscam resolver e evitar controvérsias pacificamente. Isso ocorre em comunidades de segurança, cujos membros sequer cogitam usar a violência como meio de resolver controvérsias entre si, entretanto, chegar até tal nível de maturidade nas relações interestatais envolve um processo mais complexo associado a uma profunda integração regional, ou seja, requer mais do que transparência militar (ADLER, 1998; DEUTSCH et al, 1969; HURRELL, 1998).

A formação uma comunidade de segurança depende, em parte, do engajamento, do comprometimento e da vontade política dos governos no sentido de um aprofundamento institucional da UNASUL. O ex-chanceler brasileiro Celso Amorim já explicitou essa ideia (apud REZENDE, 2015), que esteve implícita na Declaração Conjunta do Conselho de Chefes de Estado e de Governo da UNASUL de 2009, que decidiu:

Fortalecer a América do Sul como Zona de Paz, comprometendo-nos a estabelecer um mecanismo de confiança mútua de defesa e segurança, sustentando nossa decisão de abster-nos de recorrer à ameaça ou ao uso da força contra a integridade territorial de outro Estado da UNASUL (CDS; CEED, p. 19).

No fim de 2009, estabeleceu-se o mencionado mecanismo: o Plano de Medição de Gastos e Intercâmbio de Informações de 2010. Por fim, publicou-se o primeiro Registro Sul-Americano de Gastos 
Agregados em Defesa em 2012, em que consta a relação dos gastos militares de todos os doze países membros do órgão regional.

Argentina e Chile foram encarregados pela UNASUL de desenvolver a base do que se tornou o Registro Sul-Americano de Gastos Agregados em Defesa (CEED, 2011). Ambos os países já haviam estabelecido, apoiados pela CEPAL, um mecanismo de medição bilateral de gastos militares entre 1999 e 2001, e essa experiência amparou a criação de uma metodologia padronizada de registro de gastos militares da UNASUL, sem grandes inovações metodológicas (ECLAC, 2005; SAINT-PIERRE; PALACIOS JR., 2014; SILVA, 2013).

Em suma, o CDS avançou substancialmente em temas pouco imaginados uma década antes da sua criação. Além do registro de gastos militares, do compartilhamento de acordos militares, o avanço na agenda da transparência militar reforçou o sentimento de comunidade que destaca a aproximação entre Estados sul-americanos relativamente aos "outros".

Cabe uma observação sobre o papel de atores extrarregionais. É forte a influência dos EUA (principalmente por meio da Colômbia, como mencionado acima) e, presumivelmente, tem crescido o interesse da França, da China e da Rússia pela agenda sul-americana de transparência militar à medida que essas grandes potências aumentaram a sua importância como fornecedores de armamentos e parceiros em acordos militares no século XXI. Embora a literatura sobre o assunto mencione isso (ABDUL-HAK, 2013; PAGLIARI, 2009; REZENDE, 2015; VILLA; VIGGIANO, 2012), nota-se que é decrescente a influência de atores extrarregionais, inclusive a dos EUA, sobre a agenda sul-americana de transparência militar desde a criação do CDS (ABDUL-HAK, 2013; FUCCILLE; REZENDE, 2013). Por esse motivo, não se elenca a presença de atores extrarregionais entre os principais desafios para a construção da confiança recíproca via transparência militar.

\section{Desafios na construção de confiança recíproca via transparência militar}

Entre os principais desafios presentes na literatura sobre o tema estão os seguintes: (1) a incipiente institucionalização do processo (AMORIM, 2010; PAGLIARI, 2009; REZENDE, 2015), (2) o baixo nível de transparência militar no interior de alguns Estados (Luis Saint-Pierre apud REZENDE, 2015) e (3) as questões securitárias que inibem a cooperação (Pablo Celli de la Torre apud REZENDE, 2015).

Em primeiro lugar, a exigência de consenso no processo decisório do CDS por princípio impõe aos países sul-americanos o desafio de conciliar as suas diferenças de opinião para que o CDS seja efetivo em suas ações, sendo que, por enquanto, não se vislumbra um caráter supranacional. A supranacionalidade não é um requisito para desenvolver a transparência militar, mas a institucionalização da agenda sim, pois esta significaria uma menor dependência da vontade dos governantes diante da necessidade de desenvolver a agenda. A institucionalização da agenda implicaria metas mais precisas referentes à transparência militar, o fortalecimento de mecanismos de monitoramento dos acordos militares firmados, a regulamentação de problemas técnicos associados à transparência militar, a investigação de casos de descumprimento desses acordos e um entendimento sobre solução pacífica de controvérsias - considerando alguns dos aportes da 
teoria das Relações Internacionais sobre o papel de instituições na política internacional (KEOHANE, 1984; NYE JR., 2009).

$\mathrm{O}$ avanço na agenda nos primeiros anos da UNASUL-CDS dependeu fundamentalmente da proatividade de alguns líderes e da temporária convergência de interesses políticos. No caso do Brasil, durante o governo Dilma Rousseff (2010-2016) foi perceptível a estagnação nas agendas do bloco, decorrente da queda no protagonismo do país (REZENDE, 2015). Mudanças de governo, a exemplo da Argentina e do Brasil (novamente) em 2016, podem levar a retrocessos na agenda, caso não haja uma maior institucionalização. $O$ consenso genérico que existira em prol da transparência militar quando da criação do CDS não significa convergência em relação ao nível desejado de transparência militar nem ao significado desta.

Além desse desafio institucional-regional, há um segundo institucional-doméstico relativo à transparência no tratamento de assuntos militares e ao envolvimento de civis em cada país. Transparência governamental-civil e transparência militar são assuntos interligados. Com efeito, segundo as autoridades políticas da UNASUL, o desenvolvimento da metodologia de aferição de gastos militares foi, em parte, motivada pela necessidade de melhorar a transparência e a responsabilidade fiscal de políticas públicas em geral (SAINT-PIERRE; PALACIOS JR., 2014).

Presumivelmente, onde o setor público apresenta menos transparência e, portanto, menos controle civil (ex. Parlamento, imprensa, sociedade civil organizada) há razões para questionar a propensão desses países a cumprir os acordos firmados na UNASUL. Inversamente, a institucionalização do acesso à informação pela sociedade é um sinal positivo no sentido do cumprimento de acordos internacionais pelo Estado.

Nesse contexto, as variáveis que afetam negativamente a transparência militar doméstica são a falta de efetividade de políticas e a carência de planejamento militar, e a fraqueza nos controles civil e democrático sobre políticas de defesa, gastos militares e diversos tipos de contrato no setor de defesa (STOCKHOLM INTERNATIONAL PEACE RESEARCH INSTITUTE - SIPRI, 2014). A Transparency International (2013) analisa os níveis domésticos de transparência especificamente no setor de defesa. Dos 5 países sul-americanos pesquisados, Argentina, Brasil, Chile e Colômbia apresentam nível moderado de risco de corrupção, juntamente ao lado de países como Espanha, França, Itália e Japão. Neste nível, é mínimo o percentual de gastos militares confidenciais, os legisladores têm mecanismos de controle sobre as atividades do setor de defesa, e é alta a institucionalização dos processos investigativos referentes à corrupção (TRANSPARENCY INTERNATIONAL, 2011; TRANSPARENCY INTERNATIONAL, 2012a; TRANSPARENCY INTERNATIONAL, 2012b).

A Venezuela apresenta nível muito alto (acima deste há apenas o nível crítico, e abaixo deste há o nível alto), ao lado de países como Nigéria, Irã e Indonésia (TRANSPARENCY INTERNATIONAL, 2013). Este nível envolve, por exemplo, barreiras aos cidadãos do país que desejem informação sobre gastos militares, falta de autonomia para parlamentares monitorarem tais gastos e significativo risco de casos de corrupção de oficiais e de processos licitatórios (TRANSPARENCY INTERNATIONAL, 2012c). 
A centralização do processo decisório em políticas de defesa na Presidência da República e no alto comando das forças armadas, e, concomitantemente, a exclusão de instituições dos poderes Legislativo e Judiciário e da sociedade civil organizada são fatores que prejudicam a transparência militar em nível doméstico na Bolívia (ATAHUACHI, 2006) e na Venezuela (TRANSPARENCY INTERNATIONAL, 2012c), bem diferentes dos contextos da Argentina e do Brasil.

O terceiro desafio para o desenvolvimento da transparência militar refere-se ao tipo de relação bilateral de cada Estado sul-americano com seus vizinhos, que afeta decisivamente a atribuição de significado àquela agenda. Na região andino-amazônica, as experiências incipientes de construção de confiança são perturbadas por ao menos quatro controvérsias.

Três dessas são territoriais. Entre Guiana e Suriname paira desconfiança por causa da disputa pela fronteira oriental guianesa de New River Triangle (ABDUL-HAK, 2013). O pleito venezuelano por dois terços do território da Guiana a oeste do rio Essequibo também provoca similar desconfiança mútua (OTÁLVORA, 2002; PESOA; NOGUEIRA, 2004). Colômbia e Venezuela disputam a posse do mar territorial no Golfo da Venezuela (OTÁLVORA, 2002).

A quarta controvérsia é de cunho geopolítico, decorrente da presença militar dos EUA na América do Sul, à qual Equador e Venezuela têm se mostrado mais sensíveis. Os objetivos estratégicos colombianos são a consolidação do controle estatal sobre o território, a proteção da população, a eliminação do comércio de drogas ilícitas no país e a preservação da capacidade dissuasiva (COLÔMBIA, 2003), admitindo a necessidade de cooperação sul-americana no combate ao terrorismo e crimes transnacionais (EL ESPECTADOR, 2009). O tema do combate ao narcotráfico e o envolvimento dos EUA problematizam ainda mais as relações entre Colômbia, Venezuela e Equador (PAGLIARI, 2009). Equador e Venezuela interpretam a presença dos EUA como uma grave ameaça dos EUA e da Colômbia contra a soberania nacional.

\section{Considerações Finais}

A construção da agenda sul-americana de transparência militar ocorreu na esteira da criação da UNASUL e do CDS e concomitantemente à divulgação de gastos e de acordos militares. Entre 2008 e 2012, os primeiros avanços na agenda foram uma resposta com o intuito de dissipar desconfianças relativas a compras militares realizadas à época pelo Brasil e pela Venezuela, por exemplo. No período, as discussões dos Estados sul-americanos naquelas instituições regionais anunciavam formalmente um entendimento de que a promoção da transparência militar é uma boa forma de construir confiança recíproca e a paz na América do Sul.

Com o primeiro Registro Sul-Americano de Gastos Agregados em Defesa, lançado em 2012, os doze países sul-americanos fizeram algo almejado por muitas regiões do mundo, e alcançado em poucas. Entretanto, se não houver uma maior institucionalização da agenda, o estado da transparência militar na região pode ruir subitamente. De fato, até então a agenda dependeu de uma conjuntura favorável de convergência da vontade política de lideranças sul-americanas na primeira década do século XXI. Enquanto 
não se consolidarem instituições regionais capazes de liderar o avanço na agenda, esta continuará à mercê das mudanças de governo como as que vêm ocorrendo na região na segunda década do século.

Se o primeiro desafio enfrentado pela América do Sul é o da institucionalização em nível regional, o segundo desafio envolve a promoção da transparência militar de cada Estado em relação à sua sociedade. É improvável que se avance na agenda regional enquanto governos escondem dos seus próprios cidadãos as informações do setor militar. Declarações favoráveis à transparência militar no plano regional contrastam fortemente com a falta de transparência no plano doméstico em alguns países sul-americanos, a exemplo da Venezuela.

O terceiro desafio envolve uma dualidade na qual, por um lado, a transparência militar contribui para a construção de confiança recíproca, que propicia a solução de controvérsias. Por outro lado, a existência de uma controvérsia em si inibe a transparência militar, pois um Estado poderia usar a transparência militar como uma forma de obter vantagem sobre um adversário, e que o acesso a informações estratégicas seja parte de um plano para resolver à força determinada controvérsia.

Em suma, o atual estágio de transparência militar na América do Sul não é avançado nem garantido. É possível evoluir, mas também retroceder. O avanço depende da medida em que os membros da UNASUL perseguirão interesses perenes de Estado, não os efêmeros interesses de governo. Assim, haverá melhores condições para a institucionalização da agenda da transparência militar, para o aumento nos níveis de transparência domesticamente e para a priorização de soluções pacíficas das controvérsias sul-americanas.

\section{REFERÊNCIAS}

ABDUL-HAK, A. P. N. O Conselho de Defesa Sul-Americano: objetivos e interesses do Brasil (CDS). Brasília: FUNAG, 2013.

ADLER, E.; BARNETT, M. (eds). Security Communities. Cambridge, UK: Cambridge University Press, 1998.

ALSINA JR., J. P. S. Política externa e política de defesa no Brasil: síntese imperfeita. Brasília: Câmara dos Deputados, Centro de Documentação e Informação, Coordenação de Publicações, 2006.

AMORIM, C. Brazilian foreign policy under President Lula (2003-2010): an overview. Revista Brasileira de Política Internacional. 53 (special), Dec. 2010.

ATAHUACHI, D. Calidad, eficiencia y transparencia del presupuesto de defensa: El caso de Bolivia. Buenos Aires: RESDAL, ago. 2006.

BACHELET, M. Defensa: Programa de gobierno. [Santiago]: [s.n.], 2014. Disponível em: <http://michellebachelet.cl/wp-content/uploads/2013/10/Defensa-150-153.pdf>. Acesso em: 06 ago. 2014.

BANDEIRA, L. A. M. O Brasil e a América do Sul. In Relações Internacionais do Brasil: temas e agendas. Vol 1. São Paulo: Saraiva, 2006.

BERNAL-MEZA, R. Argentina y Brasil en la Política Internacional: regionalismo y Mercosur (estrategias, cooperación y factores de tensión). Revista Brasileira de Política Internacional. Brasília, v. 51, nº 2, jul.-dez., 2008. 
BRANDT, J. et al. Chinese Engagement in Latin America and the Caribbean: implications of US policy. Washington D.C.: American University, 2012.

BRASIL. América do Sul e integração regional: UNASUL. Brasília: Ministério das Relações Exteriores, 2010.

BRASIL. Tratado Constitutivo da UNASUL. Brasília: Ministério das Relações Exteriores, 23 mai. 2008. Disponível em: <http://www.itamaraty.gov.br/temas/america-do-sul-e-integracaoregional/unasul/tratado-constitutivo-da-unasul>. Acesso em: 09 ago. 2014.

BRENNAN, B. O. Evolución de la Política Internacional del Ecuador. In: Os Países da Comunidade Andina Vol. I. Brasília: FUNAG-IPRI, 2004.

BUZAN, B.; WAEVER, O. Regions and Powers: the structure of international security. Cambridge: Cambridge University Press, 2003.

CANDEAS, A. W. Relações Brasil-Argentina: uma análise dos avanços e recuos. Revista Brasileira de Política Internacional, Vol. 48, n. 1, pp. 178-213, Brasília, 2005.

CASTILlO, J. I. A. R. O Brasil e a Segurança no Cone Sul no pós-Guerra Fria. Tese (Programa de PósGraduação em Ciência Política), Faculdade de Filosofia, Letras e Ciências Humanas. São Paulo: Universidade de São Paulo, 2008.

CENTRO DE ESTUDIOS ESTRATÉGICOS DE DEFENSA - CEED. Informe Final - Diseño de una Metodología Común de Medición de Gastos de Defensa. La Paz, 29 jul. 2011. Disponível em: <http://www.ceedcds.org.ar/Espanol/09-Downloads/Metodologia_Comun.pdf >. Acesso em: 20 de abr. de 2015.

CERVO, A. L. Inserção Internacional: formação dos conceitos brasileiros. São Paulo: Ed. Saraiva, 2008.

. Relações Internacionais da América Latina: Velhos e Novos Paradigmas. Brasília: IBRI, 2001.

COLÔMBIA. Política de defensa y seguridad democrática. Bogotá: Ministerio de Defensa Nacional, 2003. Disponível em: <http://www.oas.org/csh/spanish/documentos/ Colombia.pdf>. Acesso em: 10 ago. 2014.

CONSELHO DE DEFESA SUL-AMERICANO - CDS; CENTRO DE ESTUDIOS ESTRATÉGICOS DE DEFENSA CEED. Registro Suramericano de Gastos Agregados en Defensa 2006-2010. Buenos Aires, Vol. 1, N.1, 2014. Disponível em: <http://www.ceedcds.org.ar/Espanol/09-Downloads/RSGD-20062010_ESP.pdf >. Acesso em: 20 de abr. de 2015.

COUTO, L. F. O Horizonte Regional do Brasil: integração e construção da América do Sul. Curitiba: Juruá, 2009.

COSTA, W. M.. O Brasil e a América do Sul: cenários geopolíticos e os desafios da integração. Confins Revista Franco-Brasileira de Geografia. N. 7, 2009.

DEUTSCH, K. W. et al. Political Community and the North Atlantic Area: International Organization in the Light of Historical Experience. New York: Greenwood, 1969.

DINIZ, A. M. C. Identidade, Desenvolvimento e Integração: desafios para o Brasil e a América do Sul no século XXI. In: O Brasil e a América do Sul: desafios para o século XXI. 1 ed. Brasília: Fundação Alexandre de Gusmão, 2006.

ECONOMIC COMMISSION FOR LATIN AMERICA AND THE CARIBBEAN - ECLAC. Methodology for the comparison of military expenditures. Santiago: Office of the Executive Secretary, 2005. Disponível em:

<http://www.un.org/disarmament/convarms/Milex/Docs/Resources/MethodologyForComparisonE.pdf $>$. Acesso em: 20 abr. 2015. 
ELLIS, R. E. The New Russian Engagement with Latin America: strategic position, commerce, and dreams of the past. Carlislie Barracks: Strategic Studies Institute, 2015.

ESTADÃO. Equador e Colômbia retomam relações diplomáticas. Estadão.com.br, São Paulo, 25 set. 2009a. Disponível em: $\quad<$ http://www.estadao.com.br/noticias/internacional,equador-e-colombiaretomam-relacoes-diplomaticas, 441193,0.htm>. Acesso: 25 nov. 2009.

ESTADÃO. Venezuela sugere discutir todos os acordos militares da região. 15 set. 2009b. Disponível em: $<\mathrm{http}$ //internacional.estadao.com.br/noticias/america-latina,venezuela-sugere-discutir-todos-osacordos-militares-da-regiao,434241>. Acesso em: 13 ago. 2014.

EYZAGUIRRE, J. Breve Historia de las Fronteras de Chile. Santiago de Chile: Editorial Universitaria, 1979.

FOLHA DE SÃO PAULO. Lula tenta conter tensão diplomática na região. São Paulo, 24 abr. 2008.

FOLHA DE SÃO PAULO. UNASUL põe transparência militar em pauta. São Paulo, 28 ago. 2009. Disponível em: <http://www1.folha.uol.com.br/fsp/mundo/ft2808200901.htm>. Acesso em: 15 ago. 2014.

FORTI, A. W. Lanzamiento del Registro Suramericano de Gastos Agregados en Defensa 2006-2010. Montevideo, CEED UNASUR, 16 dez. 2014. Disponível em <https://www.youtube.com/watch?v=Qp2e-nqTQqE>. Acesso: 20 jun. 2017.

FUCCILLE, A.; REZENDE, L. complexo Regional de Segurança da América do Sul: uma nova perspectiva. Contexto Internacional, v. 35, n. 1, p. 77-104, jan/jun, Rio de Janeiro, 2013.

HIRST, M. Democracia, Seguridad e Integración: América Latina en un mundo en transición. Buenos Aires: Grupo Editorial Norma S.A., 1996.

HURRELL, A. An emerging security community in South America? In Security Communities. Cambridge, UK: Cambridge University Press, 1998.

KEOHANE, Robert. After Hegemony: Cooperation and Discord in the World Political Economy. Princeton: Princeton Univ. Press, 1984.

LIMA, M. R. S. de. O lugar da América do Sul na política externa brasileira. Obras de Integração Física na América do Sul. BRASIL: Ministério das Relações Exteriores, 2007.

MAGALHÃES, D.T.D. Comunidade de Segurança: a teoria no conceito. Carta Internacional, v. 7, n. 2, p. 8198, jul-dez, São Paulo, 2012.

MEDEIROS FILHO, O. Entre a Cooperação e a Dissuasão: Políticas de Defesa e Percepções Militares na América do Sul. 2010. Tese (Doutorado). Faculdade de Filosofia, Letras e Ciências Humanas, Universidade de São Paulo. São Paulo, 2010.

NEGROPONTE, D. V. What's Putin Game in the Western Hemisphere? In: The Decline of US Power? Americas Quaterly, winter 2015.

NYE JR., Joseph S. Cooperação e conflito nas relações internacionais: uma leitura essencial para entender as principais questões da política mundial. São Paulo: Gente, 2009.

OLIVEIRA, A. J.; ONUKI, J. Brasil, Mercosul e a Segurança Regional. Revista Brasileira de Política Internacional, v.43, n. 2. Brasília, 2000.

OTÁLVORA, E. C. El Caribe y el Contencioso con Guyana en la Política Exterior Venezolana: Contraste de dos tiempos. Cuadernos del CENDES, ano 19. n. 49. pp. 103-126, jan.-abr., Caracas, 2002. Disponível em <http://www.geocities.com/otalvora/libros/guyana/artguy1.htm>. Acesso: 15 out. 2009.

PAGLIARI, G. C. O Brasil e a segurança na América do Sul. Ed. Juruá: Curitiba, 2009. 
PASSOS, J. M.; MENEZES, M. França diz ter oferta inédita ao Brasil. O Globo, Rio de Janeiro, 04 nov. 2009.

PESOA, R. R.; NOGUEIRA, J. M. Venezuela: economia, relações externas e integração continental. In: Os Países da Comunidade Andina Vol. I. Brasília: FUNAG-IPRI, 2004.

REUTERS. Venezuela acusa Colômbia de sonegar dados sobre acordo militar. 15 set. 2009. Disponível em: <http://br.reuters.com/article/topNews/idBRSPE58E0Q520090915>. Acesso em: 13 ago. 2014.

REZENDE, L. P. Sobe e desce!: explicando a cooperação em defesa na América do Sul: uma teoria realistaofensiva. Brasília: Ed. UnB, 2015.

RODRÍGUEZ, I. et al. Calidad, eficiencia, y transparencia del presupuesto de defensa: El caso de Argentina. Buenos Aires: RESDAL, ago. 2004.

ROSSI, C.. "Morales aceita que UNASUR seja mediadora na Bolívia”. Folha de São Paulo, São Paulo, 16 set. 2009.

SAINT-PIERRE, Héctor Luis; PALACIOS JR., Alberto Montoya Correa. As medidas de confiança no Conselho de Defesa Sul-americano (CDS): análise dos gastos em Defesa (2009-2012). Revista Brasileira de Política Internacional, v. 57, n. 1, p. 22-39, Brasília, 2014.

SANJUÁN, R. A. Prieto. Acuerdos de cooperación y bases militares en territorio extranjero: um "acto de agresión”. Cidade do México: Universidad Nacional Autónoma de México, 2012. Disponível em: <http://biblio.juridicas.unam.mx/revista/pdf/ DerechoInternacional/11.5/art/art2.pdf >. Acesso em: 15 ago. 2014.

SANTOS, M. H. de C. A nova missão das forças armadas latino-americanas no mundo pós-Guerra Fria: O caso do Brasil. Revista Brasileira de Ciências Sociais, São Paulo, v. 19, nº. 54, fev. 2004. Disponível em: <http://www.scielo.br/scielo.php?script=sci_arttext\&pid=S0102-69092004000100007\&lng= en\&nrm=iso>. Acesso em 09 ago. 2014.

SILVA, D. L. O Conselho de Defesa Sul Americano e a Construção da Confiança: Os Mecanismos de Transparência. Cadernos de Campo, Marília, [s.n.] 2013.

SUN TZU. A Arte da Guerra. São Paulo: Martin Claret, 2005.

STOCKHOLM INTERNATIONAL PEACE RESEARCH INSTITUTE - SIPRI. Transparency and accountability in military spending and procurement. Stockholm, 2014. Disponível em: <http://www.sipri.org/research/armaments/milex/transparency>. Acesso em: 14 ago. 2014.

TEIXEIRA, C. G. P. Brazil and the institutionalization of South America: from hemispheric estrangement to cooperative hegemony. Revista Brasileira de Política Internacional. v. 54, n. 2, p. 189-211, Brasília, 2011.

TRANSPARENCY INTERNATIONAL. Government Defence Anti-Corruption Index. International Defense \& Security Programme. London, 2013. Disponível em:

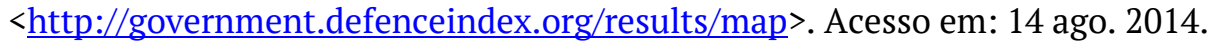

Government Defence Anti-Corruption Index: Argentina. London, mar. 2011. Disponível em: $<$ http://government.defenceindex.org/results/countries/argentina\#more>. Acesso em: 14 ago. 2014.

Government Defence Anti-Corruption Index: Brazil. London, mar. 2012a. Disponível em: <http://government.defenceindex.org/results/countries/brazil\#more>. Acesso em: 14 ago. 2014.

Government Defence Anti-Corruption Index: Colombia. London, mar. 2012b. Disponível em: $<$ http://government.defenceindex.org/results/countries/colombia\#more>. Acesso em: 14 ago. 2014. 
Government Defence Anti-Corruption Index: Venezuela. London, mar. 2012c. Disponível em: <http://government.defenceindex.org/results/countries/Venezuela\#more>. Acesso em: 14 ago. 2014.

VILLA, R. D.. Corrida armamentista ou modernização de armamentos na América do Sul: estudo comparativo dos gastos militares. [São Paulo]: Observatório Político Sul-Americano, dez. 2008. <http://www.plataformademocratica.org/Publicacoes/22070_ Cached.pdf >. Acesso em: 15 ago. 2014.

VILLA, R. D.; VIGGIANO, J. Trends in South American weapons purchases at the beginning of the new millennium. Revista Brasileira de Política Internacional, v. 55, n.. 2, p. 28-47, Brasília, 2012.

WEZEMAN, P. D.; WEZEMAN, S. T. Balancing transparency and national security. Stockholm International Peace Research Institute, Stockholm, Jan. 2014. 


\title{
RESUMO
}

Este artigo analisa a agenda da UNASUL sobre transparência militar e discute as seguintes questões: como emergiu a agenda sul-americana de transparência militar? Que significado os membros da UNASUL atribuem à promoção da transparência militar? Quais são os desafios que os Estados sul-americanos enfrentam no desenvolvimento dessa agenda? Para avançar nisso, é necessário institucionalizar a agenda da transparência militar, de promover a transparência em cada Estado sul-americano, bem como de priorizar a solução de controvérsias geopolíticas entre alguns países da região.

Palavras-chave: Transparência Militar; Segurança Regional; UNASUL.

\begin{abstract}
The present article analyzes the UNASUR agenda on military transparency, and discusses the following questions: How did the South American agenda of military transparency emerge? What does the promotion of military transparency mean to UNASUR members? What challenges do South American states face in developing this agenda? To make progress, it is necessary to institutionalize the agenda of military transparency, promote transparency within each South-American state, and prioritize the solution of geopolitical controversies that involve some states in the region.
\end{abstract}

Key-words: Military Transparency; Regional Security; UNASUR. 